\section{Pobre belleza}

Poor beauty

Carla Juaçaba

Resumen. Esta investigación se centra en un principio estético que inició en 1960 el director teatral polaco Jerzy Grotowski, en el que definió su teatro como "Teatro Pobre". Al mismo tiempo que el director de teatro inglés Peter Brook ha iniciado un proceso de búsqueda de un teatro esencial. Ambos directores repiensan el espacio teatral y su relación con el espectador, al entenderlo como un espacio democrático. Revisamos estos conceptos en el momento actual para volver a pensar en el significado de un lenguaje esencial, desde un sentido de economía, no sólo de medios y recursos sino también de acciones.

Palabras Clave

\section{Teatro pobre}

Peter Brook

Jerzy Grotowski

Esencial

octubre 2021
Bouffes du Nord
ABSTRACT. This research focuses on an aesthetic principle initiated in 1960 by the Polish theatre director Jerzy Grotowski, in which he defined Peter Brook has initiated a research towards essential theatre directors rethink the theatrical space and its relation with the spectator,

of an esseets the revisited at the present time to retrace the meaning of an essential language, from a sense of economy, not only of means and
resources but also of actions. KEY WORDS. Nature, poor theatre, Peter Brook, Jerzy Grotowski, essentizl, polish theater, Bouffes du Nord 


\section{Pobre belleza}

Este estudio surge de una admiración intelectual y estética, de un arte simple emotivo que se origina desde una realidad sociocultural donde la escasez de recursos es la fuerza motriz para la elaboración de una estética, o como reacción a un contexto político de opresión, donde el arte es un modo de expresión y revelación de una realidad.

Esta reflexión examina la investigación y trabajos desarrollados en el teatro de Jerzy Grotowski y de Peter Brook, donde se entiende el proceso como una exigente y larga búsqueda de un lenguaje esencial. Serán analizados los escenarios y espacios arquitectónicos teatrales como parte indivisible del lenguaje.

\section{El teatro pobre de Jerzy Grotowski}

“¿Puede existir el teatro sin trajes y decorados? Sí, puede.

¿Puede existir el teatro sin música que acompañe la trama? Sí.

¿Puede existir el teatro sin efectos de luz? Sí, puede.

¿Y sin texto? Sí, la historia del teatro lo confirma. En la evolución del arte teatral, el texto fue uno de los últimos elementos en añadirse.

¿Pero puede haber teatro sin actores? No conozco ningún ejemplo de esto. ¿Puede existir el teatro sin público? En última instancia, es necesario al menos un espectador para realizar un espectáculo. Nos queda, pues, el actor y el espectador. "1

Jerzy Grotowski fue un director de teatro polaco e investigador del arte de la interpretación. Entre 1957 y 1969, realizó cuatro obras - Akropolis (1962), Dr. Faustus (1963), El Príncipe Constante (1965) y Apocalipsis cum Figuris (1969) - en las que afirma un nuevo lenguaje teatral que le dio reconocimiento internacional. Su obra surgió dentro de un contexto político de posguerra, en una Polonia devastada.

En 1965 fundó el Teatro-Laboratorio, en una época de dominio de la Unión Soviética en que todas las instituciones estaban subordinadas al partido único polaco, el PZOR. Tal como analiza Lidia Olinto, su teatro coexiste con ese contexto político para que no sufriera ninguna censura: "Toda la critica al sistema realizada por el teatro de laboratorio se produjo a través de sofisticadas metáforas y simbolos menos explícitos. En su teatro habia una intención de enseñar a la gente a pensar politicamente y de que el arte fuera un encuentro con la realidad." " Su obra teatral Príncipe Constante trata sobre la independencia del individuo bajo la opresión del Estado ${ }^{3}$ donde las metáforas y símbolos fueron utilizados para hacer referencia a la tradición cristiana y a la "masacre del imaginario simbólico polaco a lo largo de la historia de Polonia”"

En el teatro de Jerzy Grotowski se eliminó todo lo que caracterizaba al teatro convencional. En su libro principal "Hacia un teatro pobre", que es la descripción de su pensamiento y su obra, propone la pobreza en el teatro, donde no hay efectos de luz, ni trajes, ni maquillaje, ni música, ni ningún otro recurso externo, sólo está el actor desnudo y esencial, con sus gestos y sus "impulsos interiores".

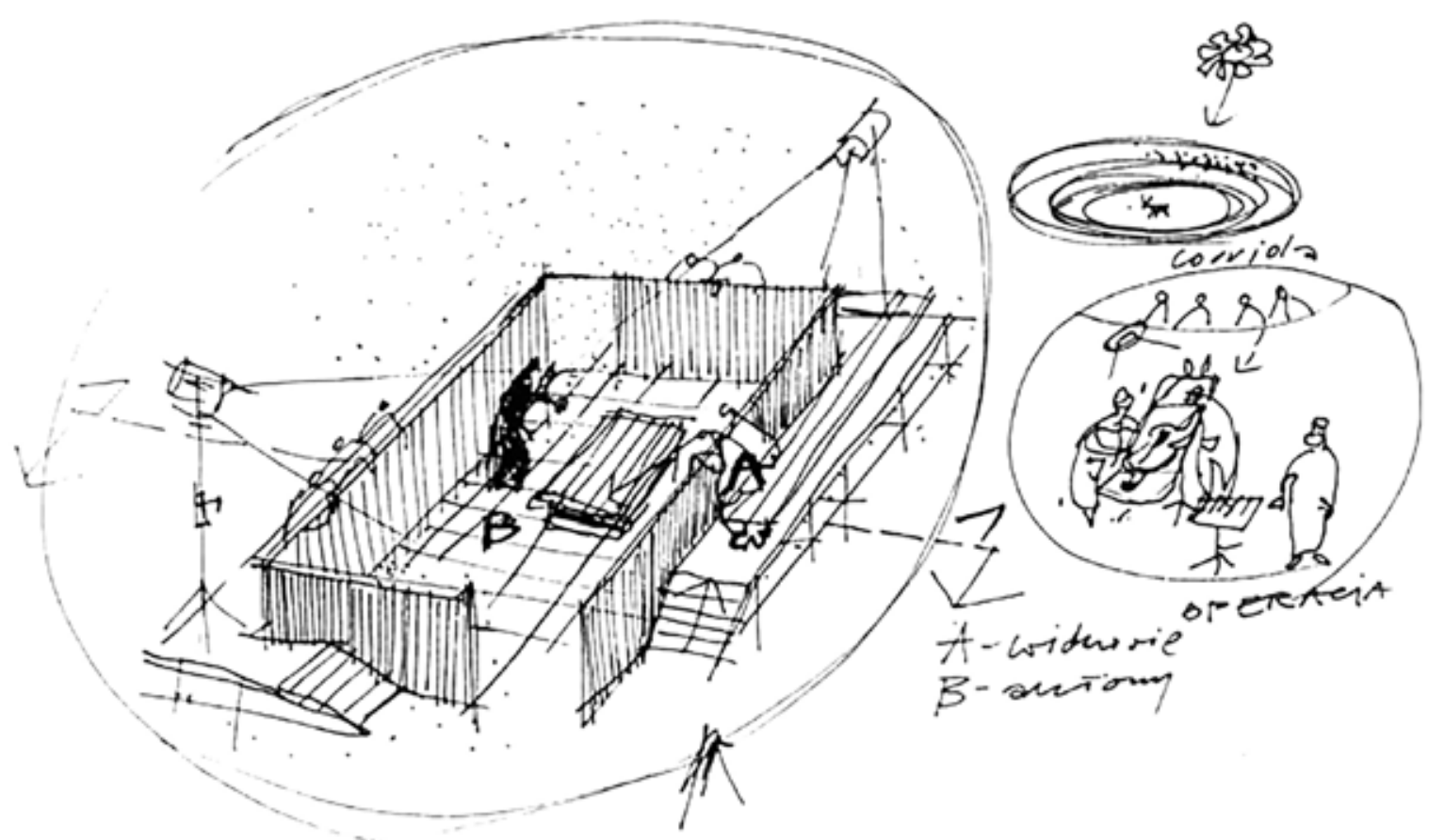

figura 1
Captura GROTOWSKI, Jerzy, Skecth for
The Constant Prince, 1965 , Design, Jerzy

The Constant Prince, 1965, Design: Jerzy
Gurawski,

Gurawski,
The Grotowsi Institute, hetrps://
grotowskinnet/en/media/galleries/jerzy

grotowskinet/cn/mcticts
gurawski-projects-06 figura 2
GROTOWSKI, Jerzy, Constant Prince,
1965, Agency AFP.

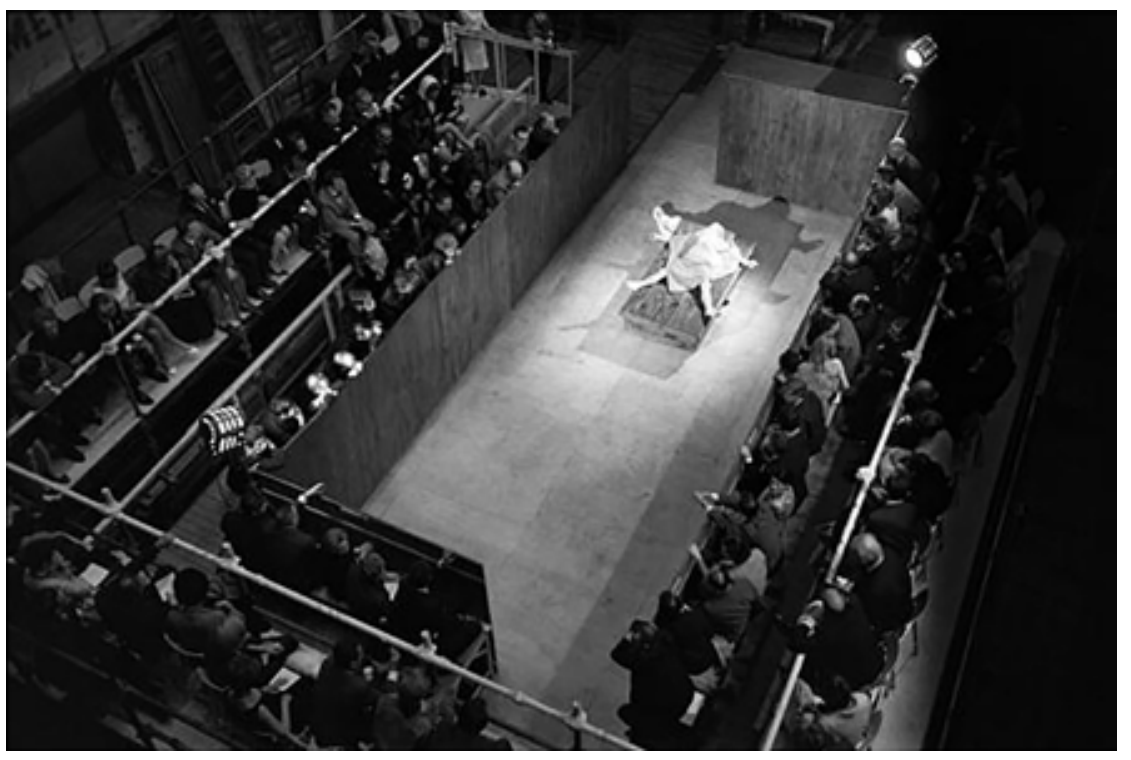


Para Grotowski, la eliminación de todos los recursos artificiales ayuda a acercarse a la naturaleza esencial del teatro. Sin embargo, aun siendo un teatro que se abstiene de cualquier otro elemento que no sea el actor y el espectador, existe un diseño para la escenografía o un rediseño del espacio teatral, en el que se busca una relación adecuada entre actor y espectador para cada tipo de presentación. Grotowski afirma que el espectador, más que un observador es un testigo. Tal como explica Raymonde Temkine en su monografía sobre Jerzy Grotowski "La mayor audacia del 'teatro-laboratorio' es superar, de forma muy decidida, el sacrosanto divorcio entre la escena y la sala. En Opole, la sala es la escena; la escena la representación, los actores caminan a su lado, actúan junto a ellos y a través de ellos."5

Por ejemplo, en la obra de Calderón El Príncipe Constante (figura1,2), el escenario tiene forma de arena donde tan solo se ven las cabezas del público, " $\mathrm{La}$ sala se construyó de forma que el público quedara casi oculto tras una pared. Observaban algo en un punto de vista muy bajo - como estudiantes de medicina que observan una operación, una cirugía psíquica- y no había relación alguna entre actores y espectadores. Ninguna." ${ }^{6}$ En este caso, el espacio arquitectónico se concentra, al mismo tiempo en que las paredes aíslan al público con la intención de transformarles en observadores, o en actores secundarios.

Esa nueva configuración fue inesperada ya que sus experiencias anteriores reunían al público y a los actores dentro del espacio de actuación. En realidad, en todas las circunstancias el publico es parte de la obra, no como actores, pero como parte esencial de la escena, complementarias al escenario.

En Kordian, los espectadores se encontraban dentro de un manicomio, sentados en camas y con camisetas de fuerza junto a los actores, constituyendo parte del drama. En Faustus (figura 3,4) utilizó Auschwitz como el "cementerio de nuestra civilización. No era posible representar Auschwitz en el teatro, ya que se podía hacer muy bien en el cine. Así no se utilizaba la ropa de los presos, sino sacos de patatas y los prisioneros trabajaban todo el tiempo. No estaban jugando a ser prisioneros, estaban en un entorno oprimido en un ambiente de trabajo absurdo. Cada actor mantenía una expresión facial particular, un tic defensivo que se elaboraba con músculos faciales sin maquillaje. Fue persona para cada uno, pero como grupo fue agonizante: la imagen de la humanidad destruida (...) Tomaron tubos de metal que estaban apilados en el centro de la sala y construyeron algo. Al principio la sala estaba vacía, al final de la producción toda la sala estaba llena, oprimida, por el metal. La construcción estaba hecha de tubos de calefacción. No hemos construido un crematorio, pero hemos dado a los espectadores la asociación del fuego. Fue indirecto, pero luego los espectadores dijeron que habíamos construido un crematorio".

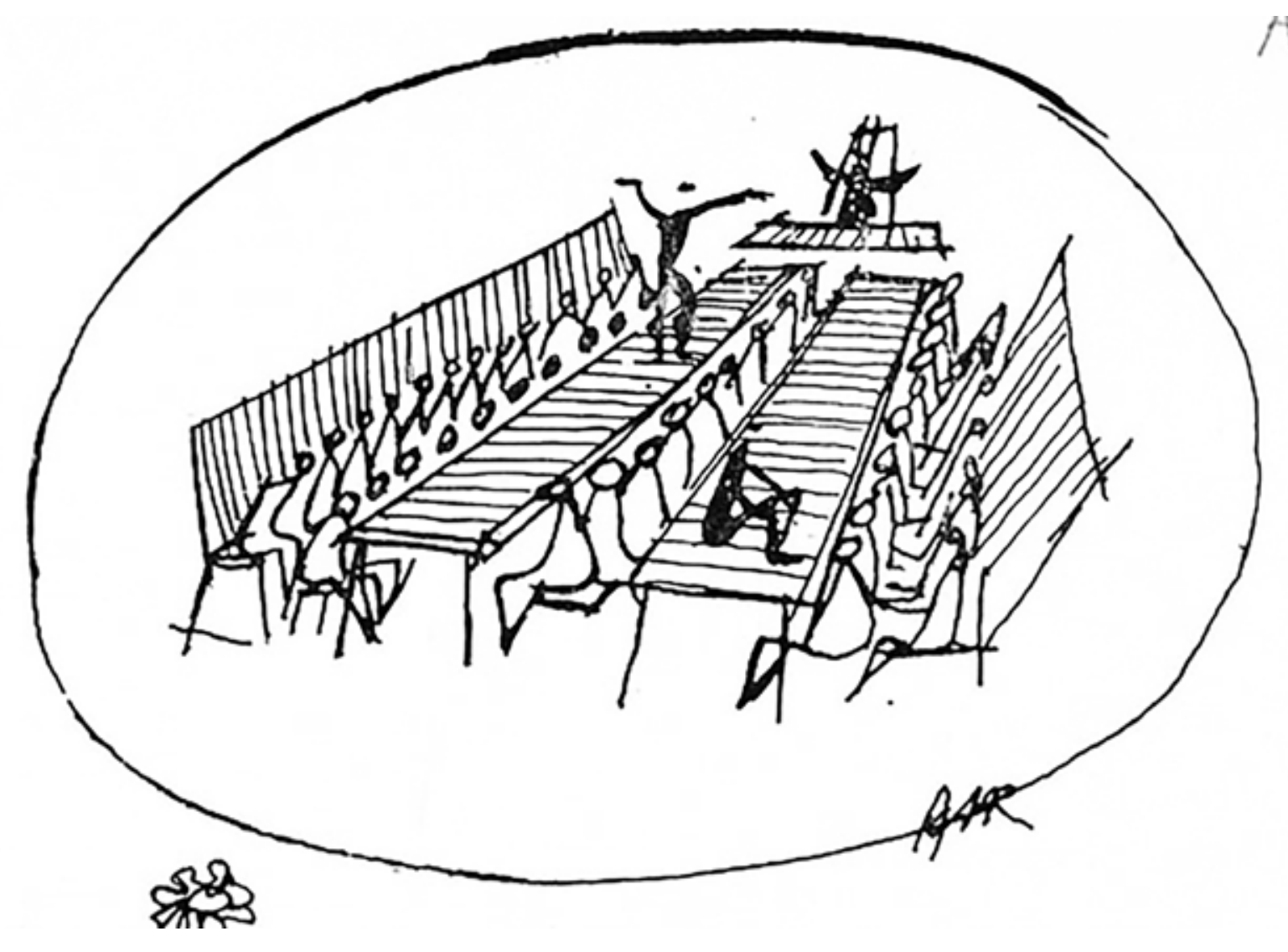

figura 3
GROTOWSKI, Jerzy, Dibujos Jerzy
Gurawski, Dr Faustus, 1963 .

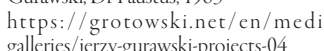

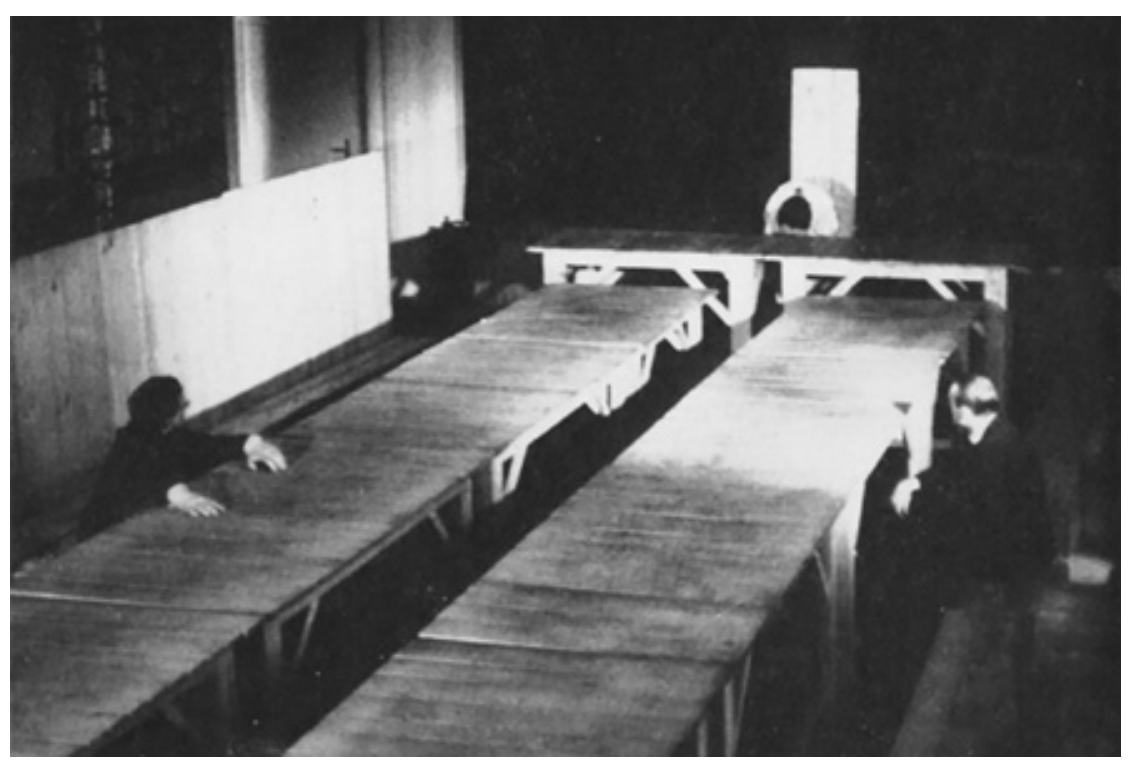


Las configuraciones espaciales se elaboraron junto con el arquitecto Jerzy Gurawski, que no era un escenógrafo. Se ve claramente que todo el espacio arquitectónico era un solo espacio sin separar el proscenio del publico, y se procuraba una dimensión concentrada siempre con un numero reducido de espectadores. También no había efectos de luz, "asi el actor tenia que trabajar con sombras y brillos, focos estacionarios, o, como figuras de pinturas de El Greco, pueden iluminar mediante técnicas personales y convertirse en una fuente de iluminación artificial"s. (figura 5,6)

\section{El espacio vacío de Peter Brook}

Peter Brook es un director de teatro inglés que vive en Francia desde los años 70, fundó el Centro Internacional de Creación Teatral- CICT con sede en el Teatro Bouffes du Nord en París desde 1974. Las grandes obras que produjeron fueron: Orghast I y II, representadas en 1971 en el Festival de las Artes de Shiraz (Irán) en las ruinas aqueménidas de Persépolis y Naqsh-e Rostam, y The Conference of Birds (La conferencia de los pájaros), desarrollada en África occidental y terminada en 1974 en el BAM de Brooklyn, Mahabharata en 1985 y La Tempête 1990, entre otros.

Empezó sus cuestionamientos sobre el espacio teatral muy temprano, caminando en África con sus actores, haciendo improvisaciones alrededor de una alfombra. Así empieza su teatro, en el suelo, con el "teatro de alfombra", donde no se necesita un techo para colgar nada, donde no hay escenario. Apenas algunos objetos o palabras son necesarios para evocar una imagen.

$\mathrm{Al}$ volver a la mas primaria de las acciones teatrales que es actuar en la calle, Peter Brook se preguntara continuamente como debería ser un Teatro: “¿Es insuficiente el espacio vacío? Si la respuesta es "sí", entonces comenzaremos a estudiar cuáles son los elementos indispensables". ${ }^{9}$

En su investigación teatral, el espacio fue parte esencial del lenguaje, así como el texto, el actor, la vestimenta, etc. Para él, era un pre-requisito la ausencia de decorado para que la imaginación funcionase: "El vacío en el teatro permite que la imaginación llene los espacios". ${ }^{10}$

Además, había una cuestión social que se buscaba en el teatro universal y también marginal ${ }^{11}$ iniciado por Shakespeare. Por eso se vuelve al diseño del teatro isabelino, donde el público se acerca a la obra. Encontrar el Teatro Bouffes du Nord en Paris fue por tanto un reconocimiento, una consecuencia de la investigación iniciada por el Centro donde hubo un encantamiento mutuo de inmediato, por las proporciones del teatro, por ser un espacio marginal de la ciudad -así como fue el teatro de Shakespeare en el Bankside-, y por estar en estado de deterioro con el decorado en ruinas. El colaborador de Peter Brook, Jean-Claude Carrière dijo que fue como un enamoramiento, "era como si nos aguardara un lugar sumido en un profundo sueño que se hubiera salvado milagrosamente de las demoliciones de los años setenta".12
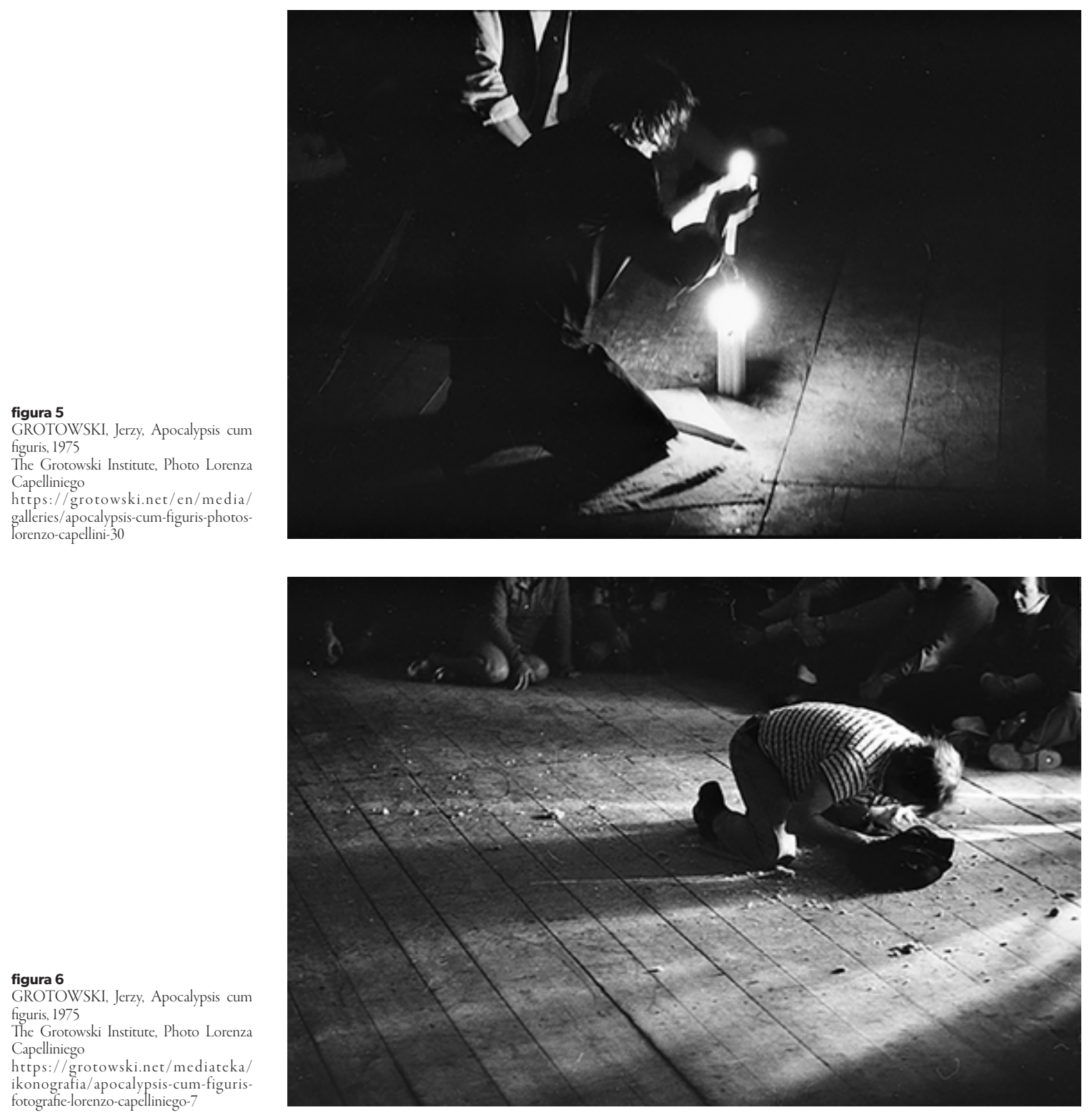
Así Peter Brook se apropió del teatro, poniendo "actores y público en un mismo espacio, las butacas de la platea tenían que estar al mismo nivel que la superficie del escenario, sin la división que separa el mundo de la obra del mundo del público."13

P. Brook decía que los espacios teatrales ilustres "crean una intimidad y una autoridad artificial, una suerte de respeto falso generado por la arquitectura"14, se buscaba entonces un espacio democrático en que aportaba una "sensación trascedente de comunión"15. (figura 7)

Se podría dividir en dos momentos la evolución del espacio teatral del CICT: en el primero se ocuparon espacios públicos en la calle para actuar. El público y los actores estaban siempre en el mismo suelo, donde son todos eran iguales. En un segundo momento, las intervenciones o construcciones eran mas sofisticadas, se transformaban teatros existentes, o se encontraba lugares como galpones, cinemas abandonados o antiguas ruinas. Algunas transformaciones han permanecido hasta hoy.

El director técnico y escenógrafo Jean-Guy Lecat visitaba las ciudades antes que el Centro llegara, para escoger el lugar donde iban a actuar. Era un trabajo intuitivo en que se hacían preguntas muy sencillas: "¿Que puede haber que sea cálido, humano, que enmarque la acción, llene la imaginación y que, sin embargo, no afirme nada?" ${ }^{16}$ En realidad, el espacio arquitectónico debería tener una relación real con la pieza, con los actores. No había escenografía ni telón de fondo, había un vinculo con materiales reales de la arquitectura y con la calidez de un espacio.

El trabajo de Jean-Guy Lecat fue complementario del trabajo de Peter Brook tras comprender el lenguaje esencial que se buscaba. En las giras, Peter Brook llegaba con el Centro y veía los espacios escogidos y transformados por JeanGuy Lecat, afirmando que: "Parte de mi trabajo ya estaba hecho ${ }^{17}$ ”. El contexto de la obra era, por tanto, la mitad del trabajo.

El centro hizo intervenciones en espacios externos como en canteras o ruinas históricas. El primer giro del Centro fue en Irán, en las Tumbas de Artajerjes II y III ${ }^{18}$, donde la tumba-templo se incorpora a la pieza. Hubo un momento en que casi se descartó esa posibilidad por problemas técnicos de iluminación y electricidad: "El grupo se dispuso a marcharse. - Esperad -dijo Brook - Supongamos que dividiéramos la obra en dos partes. La primera mitad empezaría al ponerse el sol y seguiría hasta el anochecer; nos detendríamos en un momento trágico. Luego haríamos la segunda parte al amanecer. Así no necesitaríamos iluminación”"19.

A partir de entonces, el amanecer y el atardecer forman parte del teatro de Peter Brook. Se le ocurrió, en esta primera gira del grupo, que ni la iluminación ni la escenografía eran necesarias en el teatro. Eso se dio mediante un proceso de observación y eliminación de lo que no era necesario, no de construcción.

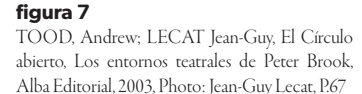

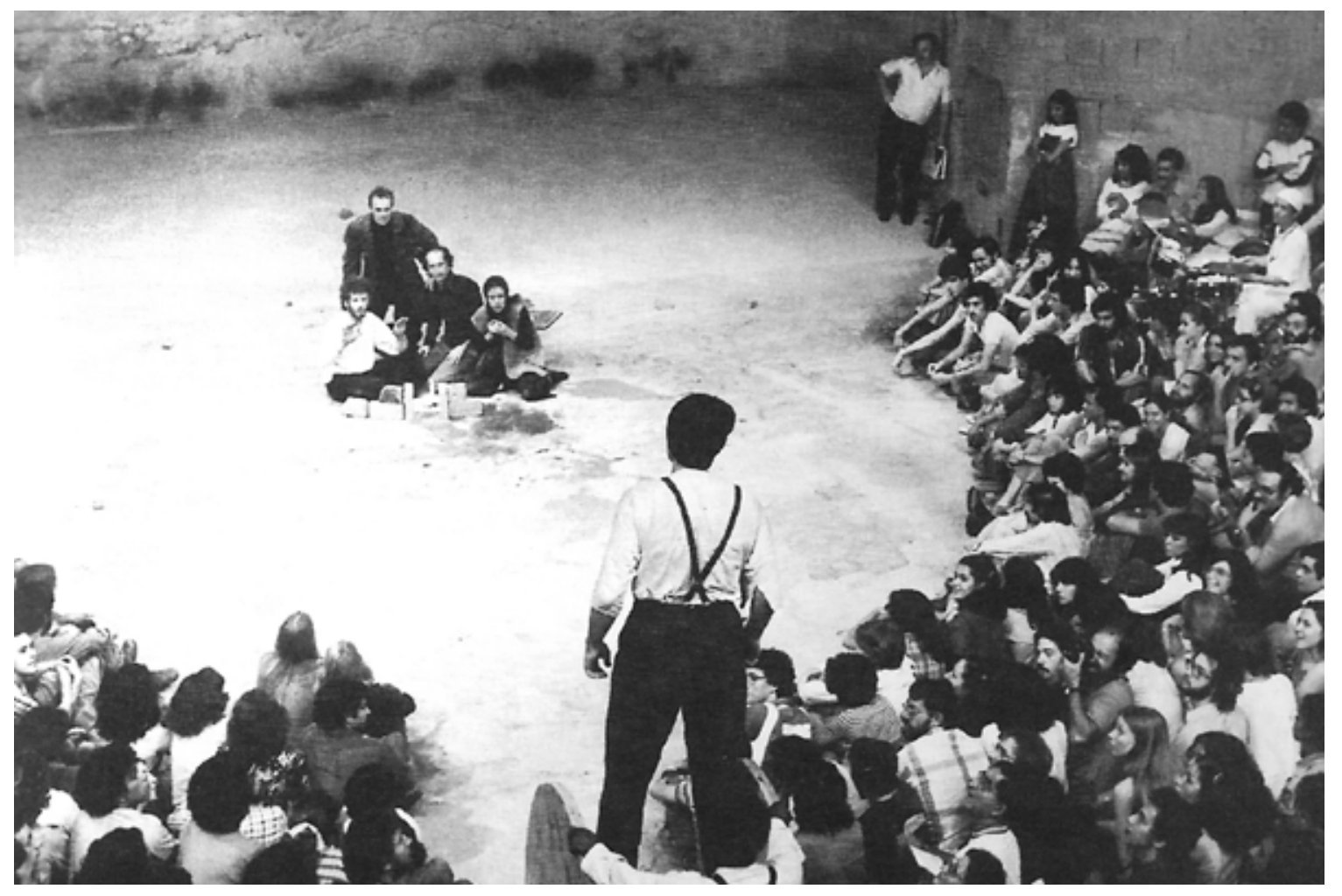


Los espacios se sucedieron y se encontraban espacios en las ciudades como un "objet trouvé". ${ }^{20}$ Donde muchas veces no se añadía nada, ni tan siquiera sillas.

En Lisboa, en el Convento do Beato António, se ocupó una diagonal del claustro con asientos, y el escenario era una alfombra.

En Adelaida, después de muchas búsquedas de un espacio teatral, se encontró una cantera con elevadas paredes de tierra donde se añadieron apenas los asientos y la iluminación.

Cuando el Centro estuvo en Belgrado (figura 8), se escogió un Cine que estaba todavía en construcción, "como se acababa de verter el cemento, las superficies eran ásperas al tacto: la tosquedad encajaba muy bien con el mundo de la obra con la dureza de la vida de la tribu en Uganda" (Les Iks, 1976).

En la universidad de Pensilvania, en el auditorio Zellerbach, se incorporó la pared de fondo del palco, sucia y maltratada y siempre oculta por las escenografías. Al final se configuró como parte de la obra como una pieza "accidentalmente viva" (Les Iks,1987).

En un segundo momento, mas elaborado, el Centro hizo por primera vez una intervención en un teatro antiguo, el Teatro Argentina (figura 9,10), en Roma (La tragédie de Carmen, 1986). El suelo del escenario se adelanta sobre las sillas, una grada con unos pocos escalones conectaba esta plataforma central con los nichos. Con eso, se ve publico desde el suelo hasta las galerías laterales.

Hicieron una transformación semejante en el Teatro de la Comedia en Madrid (Impressions de Pelléas, 1992).

En Zúrich, ocuparon un almacén industrial de metal que consideraban frío y con una mala acústica de modo que fue necesario hacer un teatro de madera dentro de la construcción acero. En el encierro del espectáculo Mahabharata, que duraba toda la noche, se abrían las puertas del galpón industrial, y "se integraba el amanecer en la acción de una forma inesperada” (The Mahabharata, Zurich, 1987).

En Barcelona, hicieron una intervención en un espacio hecho para la Exposición Universal de 1929, donde se exhibían productos agrícolas y tecnológicos. Después fue un mercado de flores. Tal como explica Jean-Guy Lecat en su libro acerca de los espacios teatrales, se encontró una calidad arquitectónica que se correspondía con lo que el Centro proponía: "tenia una pared de mampostería en la que se rasgó el yeso; una estructura de madera hecha con cientos de tablas; y el techo se cubrió con listones de madera. La zona de actuación se situó en una crujía de la estructura y la inclinación del techo de madera actuaba como difusor acústico. Se colgaron discretos focos de las vigas y se movieron unas lámparas sencillas que pendían por el resto del espacio para iluminar la sala."21

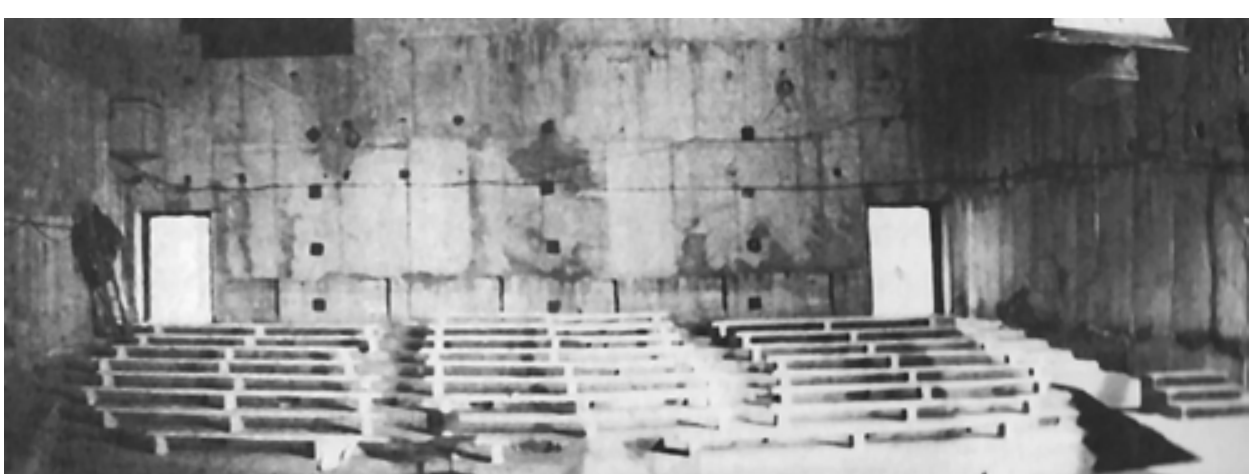

figura 8
TOOD, Andrew; LECAT Jean-Guy, El
Circulo abierto, Los entornos tearrales de

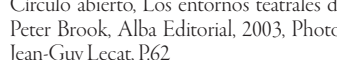
figura 9
TOOD, Andrew; LECAT Jean-Guy, El
Circulo abierto, Los entornos tearrales de

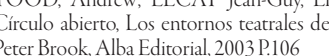

figura 10

TOOD, Andrew; LECAT Jean-Guy, El Circulo abierto. Los entornos tearales de
Peter Brook, Alba Editorial, 2003, Photo:
Jean-Guy Lecar P1 109
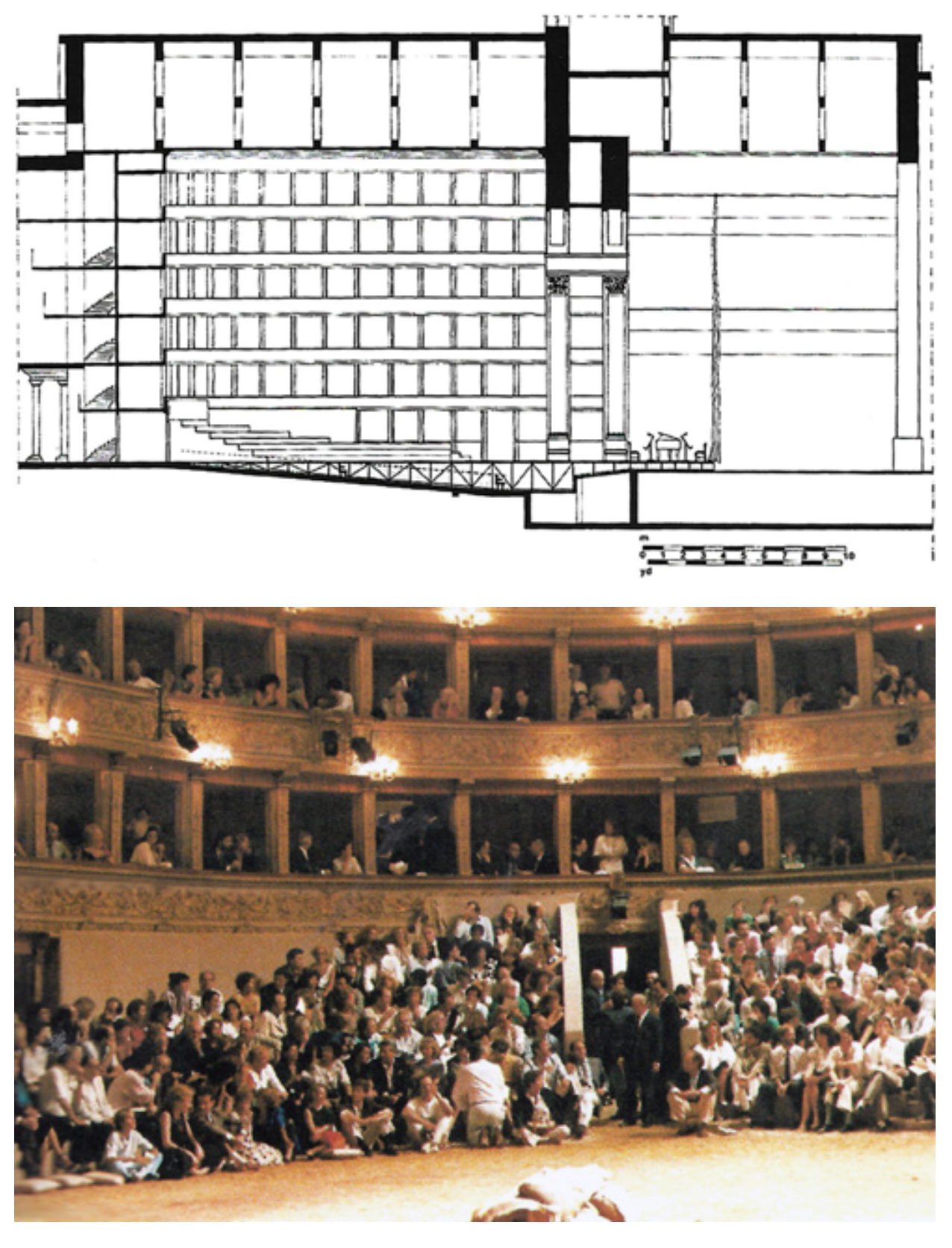
Como el espacio de Bouffes du Nord en Paris, el público culto y más convencional era invitado a adentrarse en una parte de la ciudad que no se frecuentaba.

El CITC hizo un conjunto de intervenciones de bajo costo que repiensan el espacio teatral - reflejo de la sencillez del trabajo de Peter Brook - donde se entendían las soluciones económicas como una búsqueda y como parte de un lenguaje esencial. Acercan el actor al público hasta compartir el mismo suelo, por tanto, es un espacio democrático, sin jerarquías. Al final se entiende e espacio teatral como parte de un solo lenguaje.

Jean-Guy Lecat lo describe como un trabajo "único en el sentido en el que usamos el 'espacio del lugar' como si fuera el 'espacio del espectáculo'"’22.

\section{Espacio de Comunión}

Peter Brook y Jerzy Grotowski tuvieron una larga trayectoria de encuentros, a través de visitas a los Centros, haciendo talleres con sus grupos, textos, entrevistas, etc. donde encontraron una reciprocidad. Sin embargo, Brook reconoce las diferencias sobre todo en la radicalidad del teatro de Grotowski que consideraba que practicaba como una suerte de ascesis.

Pero lo que les unía no era la forma, sino la búsqueda de la transcendencia de la vida, en "un mundo invisible que es preciso hacerlo visible".23

Las cosas no se revelan del todo, es un trabajo de analogías y metáforas donde "se estimula la imaginación del público, dejando espacio para volar"24

En el teatro de Jerzy Grotowski "El actor transforma el espacio, mediante el uso controlado de sus gestos, el suelo se transforma en mar, una mesa en un confesionario, un objeto de hierro en un compañero animado, etc. "25 Peter Brook en la pieza La Tempestad, llegó, después de muchos intentos, a la conclusión que no se debería construir un escenario de una isla sino "construir la isla en la imaginación del publico". ${ }^{26}$

Tal como explica Wendolín Ríos Valerio en su articulo sobre la imaginación simbólica en el teatro de Jerzy Grotowski, "el símbolo evoca un sentido a través de una imagen sensible, remite a un significado irrepresentable, trae al presente una ausencia, dibuja lo desconocido." ${ }^{27}$ Ambos teatros se centran en el trabajo del actor, que "debe ser capaz de expresar, a través del sonido y del movimiento, esos impulsos que están en el límite del sueño y la realidad. En definitiva, debe ser capaz de construir su propio lenguaje psicoanalítico de sonidos y gestos, del mismo modo que un gran poeta crea su propio lenguaje de palabras. Debe saber dirigir el aire y las partes del cuerpo donde se va a crear y amplificar el sonido, como en una especie de amplificador" ${ }^{28}$. (figura 11,12)

La dimensión acústica era muy importante en ambos teatros, sobre todo cuando se trabajaba con la resonancia del actor y la musicalidad de toda la actuación. La musicalidad provenía de los movimientos y del discurso de los actores.
Hubo un experimento extremo en el teatro de P. Brook cuando dirigió Orghast que se basó en una lengua imaginaria, de modo que la comprensión del texto se hacía a través de los signos y de los sonidos. Se procuraba un ritmo en los cuerpos y en el sonido, como se busca el ritmo en el poema. Como analiza Octavio Paz, el fenómeno poético vuelve al principio del habla: "El ritmo no solamente es el elemento más antiguo y permanente del lenguaje, sino que no es difícil que sea anterior al habla misma".29 Así llegan, tanto Peter Brook como Jerzy Grotowski, a la región más invisible de nuestro ser, que es la imaginación.

Es significativo como, después de analizar todos los aspectos del teatro de los dos directores, donde el ejercicio es sustraer la parafernalia escénica para llegar a la esencia del teatro, se percibi que el espacio arquitectónico no es tratado como un problema secundario, es si parte del discurso y es donde más hay dibujo: envolviendo, transformando o rediseñando los espacios existentes.
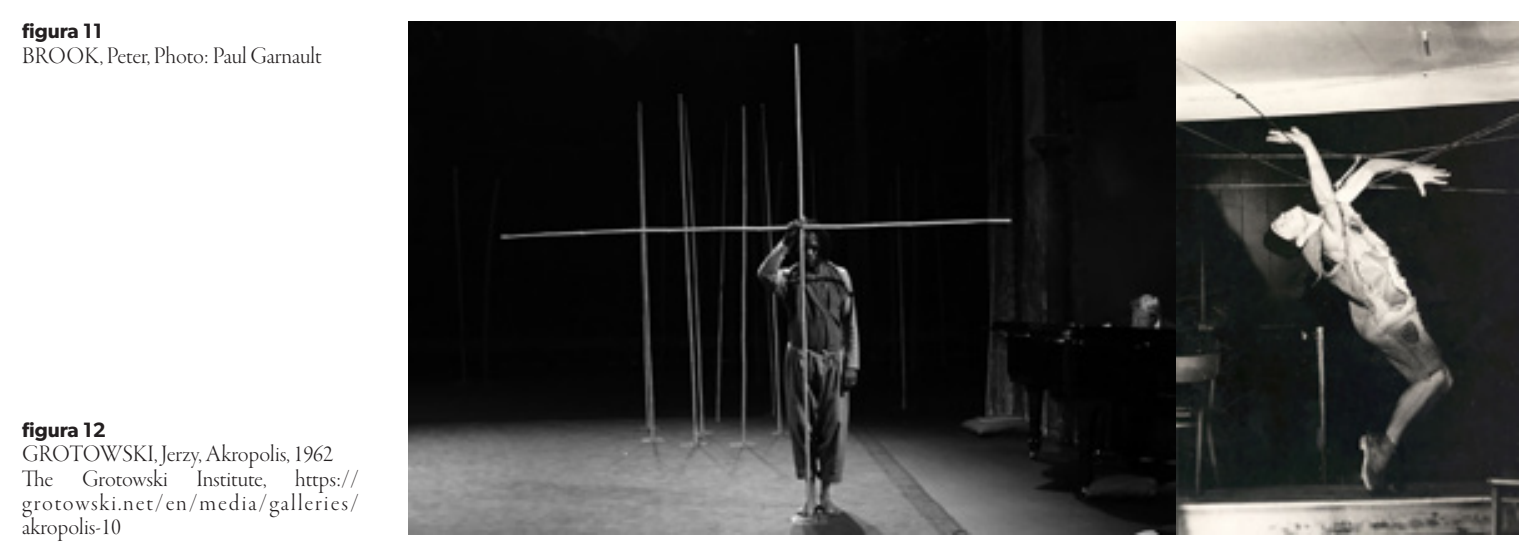
1.

GROTOWSKY, Jerzy, Em busca de um
Tearto pobre, 7 ditora Civilizaçāo Brasilei-

2. OLINTO, Lídia; CAMPOS, Karina de Almeida - Grotowski e a Politicica Rev.
Estudo. Presenç̧, Porto Alegre, v. \&, n. 1, p.

3. NUNNS, Stephen. Ludwik Flasken and Thearre December Groog

ERREIRA, Melissa da Silva. Grotowski c TEMKINE, Raymonde. Bientôt une Bien-
nale du Theartre d'Avant-Garde ? Comb

6.

GROTOWSKI, Jerzy; SCHECHNER,
Richard; CHWAT, Jaques. An Interview, Richard, CHWAT, Jaques. An Interview
with Grotowski, The Drama Review

7.

GROTOWSKI, Jerry; SCHECHNER, with Grotowski, The Drama Review vol.43, The MIT Press, 1968 p.42

8.

GRoTOWSSKY, Jerzy, Em busca de un
Tearto pobre. Editora Civilizaço Besaile

9.

BROOK, Peter, La Puerta Abierta - Re-
flexiones sobrel a actuación yel teerro Atba 10

BROOK, Peter, La Puerta Abierta - ReHexiones sobrel acct
Editorial, 1996 p.17

11.

Círculo abierto L LECAT Jean-Guy, El ster Brook, Alba Editorial, 2003 P.246

12. Círculo abiertrow; Los entornos Jean-Guy, El 13. TOOD, Andrew; LECAT Jean-Guy, El

TOOD, Andrew; LECAT Jean-Guy, El
Circulo abierto, Los entornos tearrales de Circulo abierto, Los entornos tearales
Peter Brook, Alba Editorial 2003 Pas 15. TOOD, Andrew; LECAT Jean-Guy, El
Circulo abierto, Los entornos teatrales de
Peter Brook, Alba Editorial, 2003 P.248

\section{6.}

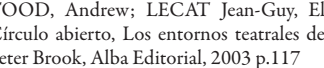

17.

Tircd, Andrew; LECAT Jean-Guy, El

18.

Gira del CICT con la pieza Orghast, Irán

19.

TOOD, Andrew; LECAT Jean-Guy, El
Circulo abierto, Los entornos teatrales de

.

20.

El principio del object trouvé, es encontrar nificado. A principio es un objeto neutro
indiferente a a bellezas

21.

TOOD, Andrew; LECAT Jean-Guy, El Circulo abierto, Los entornos teartales de
Peter Brook, Al

22.

COD, Andrew; LECAT Jean-Guy, E Circulo abierto, Los entornos teartales de
Peter Brook, Alba Editorial, 2003 p.192 23.

BROOK, Peter, La Puerta Abierta - Re-
flexiones sobre la actuación yel teatro. Alba

24.

TOOD, Andrew; LECAT Jean-Guy, El iter Brook, Alba Editorial, 2003 p.183
ingles

25.

GROTOWSYY, Jerry, Em busca de un
Tearto pobre, Editora Civilizaçąo Brasilei
la, 1987 p.19

26.

TOOD, Andrew; LECAT Jean-Guy, E .

27

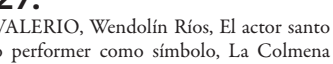
N56, octubre-diciembre 2007, p.1

28

GROTOWSKY, Jerry, Em busca de un
Teatro pobre, Editora Civilizaça Brasilei-

29.

PA. Octavio. El arco y la Lira, Fondo de
Cultura Económica, 2005 p.24

\section{Bibliografía}

BROOK, Peter, La Puerta Abierta - Reflexiones sobre la actuación y el teatro.

GROTOWSKY, Jerzy, Em busca de um Teatro pobre.

Editora Civilizaçấo Brasileira, 1987

GROTOWSKI, Jerz;; SCHECHNER, Richard; CHWAT, Jaques.

An Interview with Grotowski, The Drama Review, vol.43, The MIT Press, 1968, (http://www.jstor.org/stable/1144432)

NUNNS, Stephen. Ludwik Flasken and the Pragmatics of Grotowski.

merican Theatre, December 2009

PAZ, Octavio. Los Hijos del Limo.

Fondo de Cultura Económica, 200

TOOD, Andrew; LECAT Jean-Guy, El Circulo abierto, Los entornos teatrales de Alba Editorial, 2003

VALERIO, Wendolin Rios, Elactor santo o performer como simbol.

La Colmena N56, octubre-diciembre 2007

\section{Carla Juaçaba}

Escuela Tecnica Superior de Arquitectura de Madrid. Desde el año 2000, Carla Juaçaba desarrolla su práctica independiente de arquitectura investigación con sede en Rio de Janeiro. Su oficina se dedica actualmente Ges los

ure 2013 y el AREA Santa Sede en Ahora vive en Londres, da clases en Mendrisio Accademia en Suiza y actualmente es estudiante de doctorado en la ETSAM-UPM-Madrid.

Fuente de financiamiento Financiación propia 